\title{
INNERARITY, D. (2018). POLÍTICA PARA PERPLEJOS. BARCELONA, ESPAÑA: GALAXIA GUTENBERG.
}

Mientras que el primer lustro de esta década (2010-2015) nos mostró la indignación de algunos, que condujo a que hubiera quienes se atrevieran a afirmar que estaban listos para asaltar los cielos y hacerse con la centroizquierda del tablero político, porque el cabreo de muchos había dado origen al gobierno del pueblo, y que esto nos llevaría a desplazar a una casta inoperante, trastocando así la relación élites-ciudadanía, en suma, nos dejó una primera mitad donde los indignados dejaron de describir el mundo para transformarlo (Torreblanca, 2015), el segundo lustro nos ha llenado de perplejidad.

Después de ofrecernos el ensayo La política en tiempos de indignación (Innerarity, 2015), en Política para perplejos (2018) Daniel Innerarity nos presenta una continuación de aquel en un segundo ensayo en el que aporta una lectura bastante clara de nuestra realidad global y donde apunta una cuestión con la cual todos podemos coincidir pero que no habíamos descrito con tanta vehemencia: asistimos a una época en la que la política nos llena de desconcierto e incertidumbre. Pocos eventos parecen tener sentido y las consecuencias de estos son incalculables. Los expertos siempre aparecen después de que estos han ocurrido, con las respuestas, según ellos obvias, para todas las preguntas, pero antes de que ocurriera pocos se imaginaban que el Reino Unido abandonaría la Unión Europea, que Donald Trump sería escogido presidente de los Estados Unidos de América, que este se posicionara como favorito para reelegirse en noviembre de este año, que la ultraderecha se catapultaría como una fuerza política relevante en España o que una pandemia paralizaría al mundo en pleno siglo XXI, pero así ha ocurrido.

Sin tener toda la rigurosidad formal de un ensayo académico (un par de indicadores de esto es la ausencia de referencias bibliográficas y la inexistente citación de fuentes), este texto publicado por Galaxia Gutenberg nos aporta una revisión pormenorizada de los elementos que se han conjugado para conducirnos a este estado de perplejidad. En una introducción y 34 capítulos, agrupados en 6 partes a lo largo de 180 páginas, el autor hace un repaso de cómo nos hemos sumido en este desconcierto del que no parece que estemos próximos a salir. Aun así, nos advierte, no todo es desesperanza.

El autor nos avisa, eso sí, que la indignación que desembocó en esta perplejidad no ha sido aún superada; es decir, seguimos viendo indignación, pero la diferencia está en quiénes son ahora los indignados. No obstante, de lo que sí podemos estar seguros es que hemos arribado a una época en la que existen pocas certezas. El futuro, que hasta hace poco lo asociábamos con un avance un progreso pausado pero seguro, hoy nos resulta poco halagüeño $\mathrm{y}$, sobre todo, nos ofrece pocas herramientas para su predicción, no hay certidumbre del rumbo que tomará ese futuro. Más aún, el mismo presente es difícil de interpretar, porque la ciudadanía, afirma el autor, puede darle en cualquier momento una nueva sorpresa a los políticos. Justamente esto hace cada vez más compleja la tarea de 
los encargados de describir, analizar, interpretar y explicar los acontecimientos políticos, quienes parece que tendrán que buscar nuevas herramientas y nuevos conceptos para acercarse a la realidad.

Ahora bien, lo que Innerarity reprocha, a lo largo de todo el texto, y que parece ser uno de los ejes transversales de este, es el abandono de la labor de gobierno, la progresiva supresión de las tareas de mediación. En la gestión de lo público esto nos ha conducido a un punto, se queja nuestro autor, donde, por un lado, encontramos a quienes asumen que el contexto es absolutamente ingobernable y, consecuentemente, lo único que se puede hacer es administrarlo sin aspirar a transformarlo y, por otro, quienes desde un voluntarismo absoluto afirman, en tono algo infantilista, que el contexto puede modificarse a placer, desconociendo que existen límites a la capacidad de los gobernantes para configurar la realidad.

Lo que no deja de ser paradójico es que vivamos en una sociedad que todo lo mide, todo lo calcula, que se ha obsesionado con la idea de la transparencia y la desconfianza y, a pesar de esto, se nos hace casi imposible vislumbrar, de manera más o menos fiable, cómo será nuestro futuro. Las previsiones del porvenir hoy son más un terreno de la especulación esotérica que otra cosa.

Justamente, para el autor esto ha dado paso a una sociedad exasperada, acelerada, ansiosa. Es una sociedad en la que parece que todo cambia constantemente y donde el sufrimiento se ha globalizado. Eso sí, hemos sido incapaces de generar mecanismos de solidaridad y cooperación global que permitan gobernar los asuntos sociales en el mundo. El planeta hoy tiene más recursos a su disposición, pero son más inequitativamente repartidos. Difícilmente un momento ejemplifique mejor esta cuestión que el que estamos viviendo, la inexistencia de un mecanismo global de seguridad social y la ausencia casi absoluta de esta en algunos países han complicado todavía más la atención de la pandemia originada por el virus SarsCoV-2. Así, hemos caído en cuenta de una cuestión que apunta nuestro autor, lo económico no es el único factor de la globalización, sin un mínimo de redistribución y de reconocimiento de los otros, esta será inviable. Y al parecer esa inviabilidad nos puede aparecer porque simplemente el pueblo la rechace o bien porque alguna circunstancia ajena a nosotros, como una próxima pandemia mucho más letal revele la escasa vocación por colaborar de algunos de los actores relevantes. Lo que no parece dejar margen para la duda es un hecho, esta sociedad del vértigo y la ansiedad hoy parece añorar los días apacibles y tranquilos, parece echar de menos algunas certezas de cara al futuro.

A lo anterior hay que sumarle algo evidente, vivimos una época de enorme polarización. La política se ha convertido en una "zona de señalización escasa", sabemos dónde están los polos, pero las fronteras se han difuminado, se han tornado líquidas, en buena medida por la desaparición de las categorías clásicas de izquierda y derecha para referenciar las tendencias ideológicas, ahora lo que hay es únicamente un enorme y fluido espacio entre los polos. Sin embargo, como es indispensable simplificar los términos de la discusión en una época de gran complejidad, casi todas las conversaciones se terminan traduciendo en "nosotros 
y ellos", la élite contra el pueblo, los inmigrantes contra los nacionales, los musulmanes contra los occidentales. En cualquier caso, la clave para poder sostener un diálogo serio en este contexto de polarización -pero con fronteras difuminadas- parece ser el convencimiento de todos los actores de que eventualmente pueden llegar a ocupar las tareas de gobierno, podemos estar en desacuerdo sobre las vías para solucionar una u otra cuestión, pero es indispensable que todos nos asumamos miembros de la comunidad política para que esta no sea puesta en riesgo. Si no tomamos esa previsión, el ambiente se puede enrarecer de forma peligrosamente tóxica. Precisamente, la falta de oxígeno puede dar cabida a soluciones y mecanismos, aparentemente democráticos, que en el fondo no lo son tanto, pensar que todo se puede solventar suprimiendo la intermediación de los políticos no es menos autoritario, el referéndum y el plebiscito traen aparejadas amenazas para la democracia, porque aumentan la polarización, menoscaban el valor de la representación y anulan la negociación, en los juegos de suma cero, el pacto implica un desperdicio de energías.

En medio de esto, el mundo, en un contexto de polarización creciente, vio llegar al poder de una potencia mundial a un hombre que encarna el conservadurismo, el aislamiento, la antiglobalización y el rechazo del multiculturalismo y del multilateralismo como pocos. Somos testigos presenciales de una época donde la política ha dejado de ser practicada como un ejercicio de virtudes cívicas, para ser concebida como una simple competencia por el poder, no como una ruta para mejorar la vida de las personas. Al mismo tiempo, el capitalismo salvaje parece haber conseguido imponerse, lo que ha destruido el valor del trabajo humano en su afán de maximizar la rentabilidad.

La única solución, o el único mecanismo de contención para los efectos no deseados derivados de este tiempo aciago, parece ser la configuración de sistemas inteligentes, es decir, entramados institucionales robustos que permitan sobrellevar a los malos gobernantes y, en ese sentido, sean capaces de limitar eficientemente el poder. Estos sistemas deben tener la posibilidad de protegernos incluso de nuestras malas decisiones políticas, porque es verdad que el progreso humano depende de que estas sean ejecutadas, pero también de que la arbitrariedad encuentre cortapisas, que contemos con dispositivos que sirvan como cortafuegos frente a los gobernantes autoritarios en momentos de volatilidad y ebullición como el presente. En cualquier caso, es indispensable retomar la política y la democracia como ejercicios de negociación permanente, donde las personas (los gobernantes) sean relevantes, pero más aún los sistemas en los que ellas se insertan, pues el bien común debe sobreponerse a los intereses de los triunfadores coyunturales, para ello, según Innerarity, es indispensable que sustituyamos, al menos en parte, el triángulo competición/mayoría/publicidad por el de cooperación/acuerdo/negociación, es decir, resulta imperativo diseñar mecanismos que reduzcan la importancia de la dimensión competitiva de la democracia y acentúen la trascendencia de su faceta colaborativa. 
A pesar del tiempo de incertidumbre que vivimos, de extrema volatilidad, en el que tenemos pocas cosas bajo control, en buena medida porque el espacio abierto en el que vivimos es susceptible de colapsar por una pandemia, un descalabro financiero, un ataque terrorista o la realidad inevitable del cambio climático, Innerarity concluye que no nos queda, como apuesta, más que ser optimistas, porque el pesimismo pone fin la conversación y nos deja sin una ruta que buscar, sin un camino que explorar. El optimismo, afirma, es la apuesta por la provisionalidad, es la esperanza de que habrá un mañana donde se pueda trabajar por reducir las brechas, por crear condiciones de equidad, por reparar las injusticias. Puede, así lo sostiene, que nuestro escenario actual no sea el mejor posible, pero justo ahí está la clave por el optimismo, que hay otras rutas y otros destinos posibles. "Que haya mundos posibles es la mejor garantía de que el optimismo no es algo injustificado" (p. 179), justamente por esto nuestro autor rechaza el dogmatismo del pesimista, quien cree que ya está todo dado y todo definido y quien tiende a idealizar el pasado.

En suma, el texto de Innerarity abre con un golpe de realidad, describiendo cómo hemos llegado a la perplejidad, pero cierra con un llamado al optimismo, que se puede englobar en una idea: mientras haya vida, mientras haya tiempo para cambiar nuestro escenario, hay esperanza.

Alejandro J. Robles Leal aroblesleal@gmail.com Abogado. Letrado del Tribunal Supremo de Elecciones. San José, Costa Rica.

\section{FUENTES CONSULTADAS}

Innerarity, D. (2015). La política en tiempos de indignación. Barcelona, España: Galaxia Gutenberg.

Torreblanca, J.I. (2015). Asaltar los cielos. Podemos o la política después de la crisis. Barcelona, España: Debate. 